\title{
APLIKASI PENCARIAN ALAMAT TUJUAN BERBASIS ANDROID (STUDI KASUS DAERAH BANDA ACEH)
}

\author{
Abdul Rahman ${ }^{(1)}$, Zalfie Ardian ${ }^{(2)}$ \\ Prodi Teknik Informatika, Fakultas Ilmu Komputer, Universitas U'Budiyah Indonesia \\ Jl. Alue Naga, Tibang, Kec. Syiah Kuala, Banda Aceh, Indonesia \\ Email: badellmaman@gmail.com ${ }^{(1)}$,zalfie.ardian@uui.ac.id(2)
}

\begin{abstract}
The large number of addresses that do not response make people confused to find their destination addresses with ease. So often someone getting lost or wrong destination in the search for addresses. Banda Aceh became one of the cities with high visitor levels in Aceh. Of course not everyone can know all the addresses of government offices, hospitals and schools in Banda Aceh. By looking at the problems that have been found above, can be given a solution with builds an Android-based application that serves as a medium of information to search for the destination address. It needs a system that can accommodate any type of address it into one, so that when someone wants to find the destination address, it can easily find detailed information, with quick, precise, and accurate. Simply by typing in keywords in a Search engine's search menu that becomes available, then the system will process the database to match the right keywords so found and according to the expectations of the users. This application is formed above the JAVA programming language as the algorithms and data structures and XML programming language as the language of the form interface or layout application. The exchange of data on the application form the above JSON using PHP programming language later in the java programming language captures the results of a data comes from the database in the form of JSON. Expected with the search applications this address can make it easier to seek and find the destination address with ease.
\end{abstract}

Keywords : Address, Android, JAVA, JSON, PHP

\section{PENDAHULUAN}

\subsection{Latar Belakang}

Telepon selular (smartphone) telah berubah menjadi salah satu perangkat multi fungsi, salah satu yang banyak digunakan sekarang ini adalah Android yang sistem operasinya menggunakan linux. Android lebih banyak digemari masyarakat karena pengguna bisa mengunduh aplikasi - aplikasi yang menarik dan bermanfaat bagi kehidupan sehari-hari dari Play Store. Tentunya semua tempat ataupun lokasi mempunyai alamat sebagai identitas utama untuk bisa melakukan berbagai aktifitas dalam kehidupan sehari - hari. Sebagai contoh jika seseorang ingin membuat Surat Ijin Mengemudi (SIM), maka kantor polisi lah yang menjadi tujuan sesorang tersebut. Dengan demikian, alamat sangatlah penting agar seseorang lebih mudah dalam mencari lokasi tujuan sehingga bisa menentukan alat transportasi yang tepat dan jalur mana yang harus dilalui. Banyaknya alamat yang tidak terdata membuat orang - orang bingung untuk menemukan alamat tujuan mereka dengan mudah. Sehingga sering sekali seseorang tersesat atau salah tujuan dalam mencari alamat. Banda Aceh menjadi objek dalam penelitian ini, Hal ini disebabkan kota Banda Aceh menjadi salah satu kota dengan tingkat pengunjung yang tinggi di aceh. Masih banyak orang yang belum mengetahui dengan akurat informasi alamat yang pada sekitaran Banda Aceh. Salah satu penyebabnya karena papan nama jalan yang memandu ke lokasi alamat terkadang tidak tersedia, rusak, ataupun hilang. Google Map sebagai sebuah layanan menampilkan map dengan sangat baik juga tidak dapat menampilkan semua jenis lokasi alamat yang inigin dituju. Seperti contoh, pencarian SMA Negeri 16 Banda Aceh. Google map belum mengetahui letak dari lokasi tersebut dikarenakan lokasi SMA Negeri 16 Banda Aceh sendiri baru saja rampung pada beberapa tahun terakhir ini. Dengan melihat permasalahan yang telah ditemukan diatas, dapat diberikan solusi dengan membangun sebuah aplikasi berbasis Android yang berfungsi sebagai media informasi untuk mencari alamat tujuan. Maka dari itu dibutuhkan sebuah sistem yang dapat menampung semua jenis alamat itu menjadi satu, sehingga ketika seseorang ingin mencari alamat yang dituju, maka ia dapat dengan mudah menemukan dengan informasi yang detail, cepat, tepat, dan akurat. Aplikasi akan berfokus pada alamat kantor pemerintahan, sekolah dan rumah sakit. Setiap daerah pasti mempunyai kantor pemerintahan yang meliputi organisasi kementerian / departemen, 
Lembaga Pemerintah Non Departemen, kesekretariatan lembaga tinggi negara, dan instansi pemerintah lainnya. Sekolah dan rumah sakit juga menjadi hal yang penting untuk diketahui alamat dengan akurat. Itu menjadi hal yang patut diperhatikan jika seseorang tidak mengetahui alamat tujuan, karena akan menghambat suatu keperluan seseorang dan menguras waktu untuk mencari alamat tersebut. Hanya dengan mengetikkan kata kunci pada menu Search engine pencarian yang telah tersedia, maka sistem akan memproses database untuk mencocokan kata kunci tersebut sehingga ditemukan dan sesuai dengan harapan pengguna. Segala informasi yang serupa juga akan tampil, sehingga dapat menghilangkan keraguan pengguna ketika mencari alamat. Informasi yang detail dan akurat menjadi pokok utama dalam aplikasi ini, juga dengan tampilan user interface yang bagus dan user friendly. Cara kerja aplikasi nantinya berupa Android harus melalui PHP (Hypertext Prepocessor) untuk mengambil data dalam database MySQL. Android tidak bisa mengirimkan permintaan data secara langsung ke database sehingga harus melalui PHP. PHP mengirimkan Query ke database yang kemudian data tersebut diproses dan ditampilkan dalam format JSON. Format JSON inilah yang akan diterima oleh android sebagai data yang di ambil dari database.

\subsection{Rumusan Masalah}

Berdasarkan latar belakang diatas maka identifikasi masalah dalam penelitian ini adalah:

a. Banyaknya alamat yang tidak terdata membuat orang - orang bingung untuk menemukan alamat tujuan mereka dengan mudah.

b. Masih banyak orang yang belum mengetahui dengan akurat informasi alamat yang pada sekitaran Banda Aceh.

c. Penyebabnya karena papan nama jalan yang memandu ke lokasi alamat terkadang tidak tersedia, rusak, ataupun hilang.

d. Google Map juga tidak terlalu detail dalam menampilkan lokasi alamat.

\subsection{Batasan Masalah}

Batasan masalah dalam penelitian ini adalah:

a. Alamat yang akan disajikan akan terbagi menjadi beberapa kategori, yaitu: Rumah Sakit, Kantor pemerintahan, Sekolah Menengah Atas (SMA / MA) menjadi tujuan utama dalam Aplikasi ini.

b. Aplikasi ini bersifat client dan server, sehingga membuttuhkan koneksi internet untuk dapat komunikasi data.

c. Integrasi data dengan database menggunakan webservice JSON sebagai format pertukaran data.

\subsection{Tujuan Penelitian.}

Tujuan yang ingin diperoleh dari skripsi ini yaitu, merancang dan membangun suatu sistem pencarian alamat yang lengkap dan cepat sehingga nantinya dapat diakses dengan mudah pada smartphone Android.

\subsection{Manfaan Penelitian}

Adapun Manfaat dari penelitian ini adalah sebagai berikut:

a. Untuk mendapatkan informasi terkini dan bisa digunakan untuk mencari alamat dengan biaya yang cukup murah bagi user.

b. Memudahkan mencari dan menemukan alamat hanya dengan satu kunci pencarian.

c. Kemudahan dalam mengakses sistem informasi modern.

\subsection{Keaslian Penelitian}

Pada penelitian Greace Widyastuti, S.Kom dan Afriyudi, M.kom. Perangkat Lunak Pecarian Alamat dikota Palembang Berbasis WAP. Menghasilkan mencari alamat berdasarkan katagori yang diinginkan yaitu, alamat rumah sakit, alamat hotel, alamat kampus/universitas, alamat kantor, dan lokasi spbu. Sehingga dapat diharapkan mempermudah user dalam melakukan pencarian alamat tanpa membuang - buang waktu dan biaya yang murah. Sehingga diharapkan dapat membantu pengguna atau user dalam mencari alamat yang dibutuhkan. Perbedaan dengan yang akan di teliti ialah Aplikasi berjalan pada sistem operasi berbasis Android. Android sudah mendukung sistem yang lebih canggih dari pada WAP. Diharapkan aplikasi nantinya dapat memberikan informasi terkini mengenai alamat yang dituju dan bisa digunakan menentukan jenis transportasi apa yang akan digunakan untuk sampai ke alamat tersebut.

\section{TINJAUAN PUSTAKA}

\subsection{Alamat}

Menurut Widyastuti (2012:5), Alamat merupakan tempat yang menjadi tujuan dimana suatu objek berada, dengan mengetahui alamatnya maka kita bisa mengetahui letak dari objek yang akan kita tuju tersebut.

\subsection{Aplikasi}

Ada banyak pengertian mengenai aplikasi oleh para ahli dalam situs www.ilmukomputer.com yaitu:

a. Aplikasi adalah satu unit perangkat lunak yang dibuat untuk melayani kebutuhan akan beberapa aktivitas (Buyens, 2001).

b. Menurut Dhanta (2009:32), aplikasi (application) adalah software yang dibuat oleh suatu 
perusahaan komputer untuk mengerjakan tugastugas tertentu, misalnya Microsoft Word, Microsoft Excel.

\subsection{Android}

Menurut Huda (2013:16), Android merupakan sebuah sistem operasi Linux yang didesain khusus untuk perangkat bergerak seperti smartphone atau tablet. Sistem operasi Android bersifat open source sehingga banyak sekali programmer yang berbondong - bondong membuat aplikasi maupun memodifikasi sistem operasi ini. Berdasarkan informasi dari situs resmi www.android.com, setiap hari terdapat lebih dari satu juta perangkat Android diaktifkan dan diperkirakan akan terus meningkat.

\subsection{Eclipse}

Menurut Noviani (2011:2), Eclipse adalah sebuah IDE (Integrated Development Environment) untuk mengembangkan perangkat lunak dan dapat dijalankan di semua platform (platform-independent).

\subsection{Android SDK}

Menurut Damarullah (2013:81), Android SDK merupakan tools bagi para programmer yang ingin mengembangkan aplikasi berbasis Google android. Android SDK mencakup seperangkat alat pengembangan yang komprehensif. Android SDK terdiri dari debugger, libraries, handset emulator, dokumentasi, contoh kode, dan tutorial.

\subsection{JDK (Java Development Kit)}

Menurut Zulfikri (2012:6), JDK adalah software development kit yang digunakan dalam pemrograman bahasa java. Jadi kalau ingin belajar bahasa java, minimal yang harus ada dalam mesin komputer adalah jdk tersebut. Di dalam jdk itu ada sesuatu yang dinamakan JRE (Java Runtime Environment).

\subsection{Konsep Dasar Java Script Object Notation (JSON)}

Menurut sistus www.json.org, JSON (JavaScript Object Notation) adalah format pertukaran data yang ringan, mudah dibaca dan ditulis oleh manusia, serta mudah diterjemahkan dan dibuat (generate) oleh komputer.

\subsection{Google Map Service}

Menurut Mahdia (2013:164), Google Map Service adalah sebuah jasa peta global virtual gratis dan online yang disediakan oleh perusahaan Google. Google Maps yang dapat ditemukan di alamat http://maps.google.com.

\subsection{Global Positioning System (GPS)}

Menurut mahdia (2013:165), GPS atau Global Positioning System, merupakan sebuah alat atau sistem yang dapat digunakan untuk menginformasikan penggunanya dimana lokasinya berada (secara global) di permukaan bumi yang berbasiskan satelit. Data dikirim dari satelit berupa sinyal radio dengan data digital.

\subsection{Unified Modeling Language (UML)}

Menurut mahdia (2013:164), UML (Unified Modelling Language) merupakan bahasa pemodelan grafis yang digunakan untuk mendesain dan membantu pendeskripsikan sistem perangkat lunak, khususnya sistem yang berorientasi objek. UML mencakup berbagai masalah yang meliputi spesifiasi, visualisasi, konstruksi, dan dokumentasi berbagai jenis perangkat lunak sistem, perangkat lunak nonsistem, dan model bisnis

\section{METODOLOGI PENELITIAN}

\subsection{Metode Penelitian}

Aplikasi ini dirancang atau dibuat dengan bahasa pemograman java dan pemograman php sebagai server dari aplikasi ini. Dalam penelitian ini penulis menggunakan model pengembangan waterfall (analisis persyaratan sistem, analisis kebutuhan perangkat lunak, desain/rancangan sistem, pengkodean program, implementasi/penerapan, pengujian, penggunaan produk, pemeliharaan/perawatan. Perancangan dan pengembangan media pembelajaran menggunakan model pengembangan perangkat lunak melalui 5 tahap yang meliputi, dapat dilihat pada Gambar 3.1. Tahapan Umum Pengembangan Aplikasi.

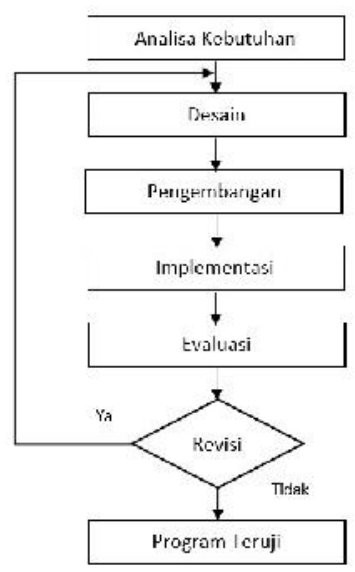

Gambar 3.1. Tahapan Umum Pengembangan Aplikasi 
Journal of Informatics and Computer Science Vol. 5 No. 1 April 2019

Universitas Ubudiyah Indonesia

e-ISSN : 2615-5346

\subsection{Populasi dan sampel}

Populasi yang digunakan sebagai objek pada penelitian ini adalah mahasiswa yang aktif di universitas ubudiyah Indonesia pada tahun 2015/2016 terutama fakultas Ilmu Komputer. Berdasarkan data dari sistem informasi akademik jumlah mahasiswa aktif yaitu 600 orang. Penetapan sampel yang digunakan dalam penelitian ini menggunakan jenis metode random sampling. Dan setelah dihitung menggunakan rumus Slovin, maka didapat jumlah sampel sebanyak 30 orang.

\subsection{Teknik Pengumpulan Data dan Sumber Data 3.3.1. Studi Pustaka dan observasi}

Teknik pengumpulan data yang dilakukan penulis adalah Studi Pustaka. Studi Pustaka dilakukan untuk mendapatkan informasi yang relevan. Penulis melakukan studi pustaka dengan mencari informasi maupun teori dari beberapa sumber referensi, jurnal, artikel. Observasi Melakukan peninjauan langsung di lapangan, hal ini dilakukan untuk memperoleh sejumlah informasi secara akurat. Penulis melakukan pengukuran letak koordinat lokasi dengan mengukur latitude dan longitude. Sumber data dapat diproleh dari mengimputan semua alamat berdasarkan kategori yang telah disebutkan sebelumnya pada seputaran Banda Aceh.

\subsection{Peralatan dan bahan}

Peralatan yang digunakan dalam penelitian ini di spesifikasikan dalam hardware dan software, yaitu sebagai berikut:

1. Perangkat keras atau hardware yang terdiri dari:

a. Perangkat komputer dengan spesifikasi Processor Amd A8 CPU @ $210 \mathrm{Ghz}$ (4 CPUs), Harddisk 500 GB, RAM 4.00 GB. Perangkat ini nanti akan digunakan sebagai alat perancangan aplikasi ini.

b. Smartphone Android (Samsung Galaxy Mini 2 Jelly Bean 4.2.2 version). Perangkat ini nantinya akan digunakan sebagai alat uji coba atau pengujian aplikasi ini.

2. Perangkat lunak atau software, yang terdiri dari :

a. Java Development Kit (JDK), sebagai jembatan bahasa program java dengan komputer agar komputer mampu mengenal bahasa java.

b. Eclipse, sebagai IDE (Integrated Development Environment) atau editor dalam membuat pemrograman android.

c. Android SDK, sebagai tools API (Application Programming Interface) yang diperlukan untuk mengembangkan aplikasi pada platform android menggunakan bahasa pemrograman java. d. (Android Developers Tools), fungsinya sebagai membuat Eclipse terhubung dengan android SDK, sehingga bias membuat pemrograman android lewat Eclipse.

3. XAMPP (Apache Mysql Php), fungsinya sebagai database server agar bisa kolaborasi Android dan PHP dengan Mysql

\subsection{Pemodelan dengan ERD (Entity Relationship Diagram)}

Perancangan Entity Relationship Diagram dari tabel database diatas dilihat pada Gambar 3.2. ERD (Entity Relationship Diagram).

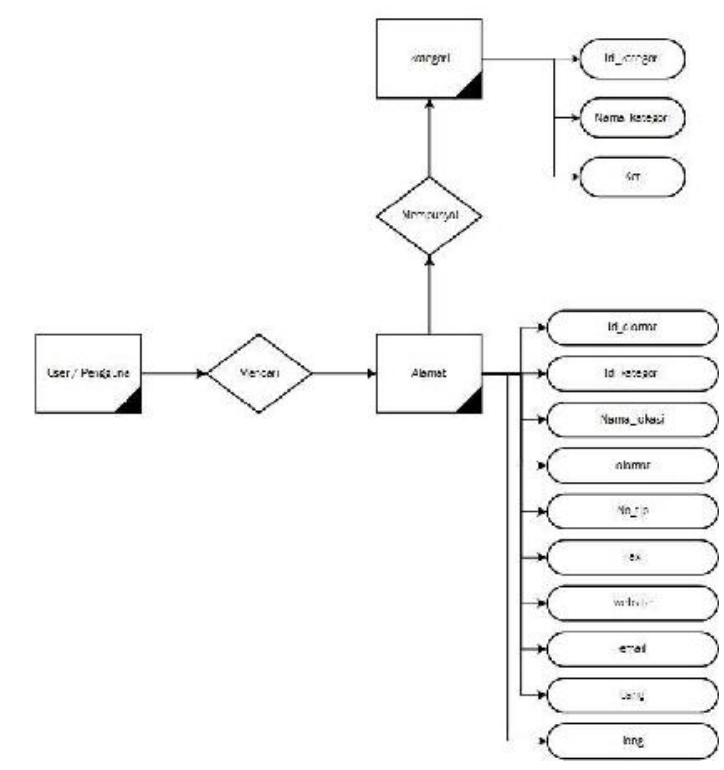

Gambar 3.2. ERD (Entity Relationship Diagram)

\subsection{Perancangan Aplikasi}

Perancangan dan pengembangan aplikasi menggunakan model waterfall. Model ini mengusulkan sebuah pendekatan kepada perkembangan software yang sistematik dan sekuensial pada tingkat dan kemajuan sistem pada seluruh analisis, desain, kode, pengujian, dan pemeliharaan. Tahapan perancangan aplikasi pencarian alamat berbasis android dapat dilihat pada Gambar 3.3. Tahapan Model Waterfall. 


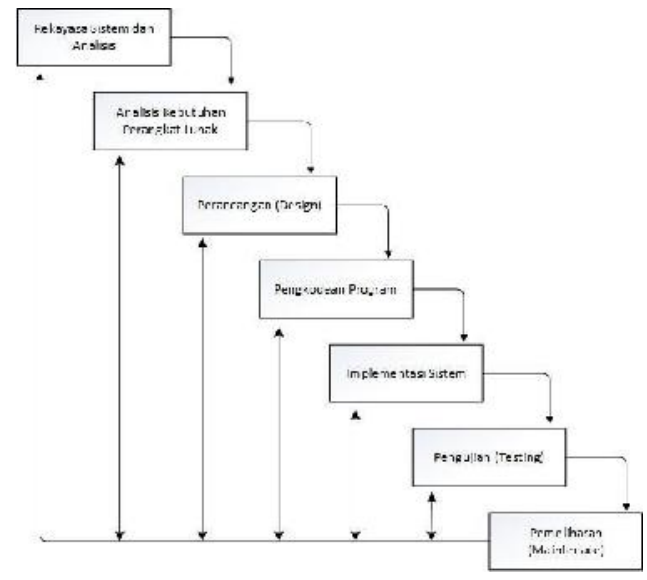

Gambar 3.3. Tahapan Model Waterfall

\subsubsection{Use case diagram}

Diagram Use Case merupakan gambaran grapichal dari beberapa atau semua aktor, use case, dan intraksi di antara komponen-komponen tersebut yang di perkenalkan suatu sistem yang akan di bangun, dapat diihat pada Gambar 3.4. Use Case Diagram User dan Administrator.

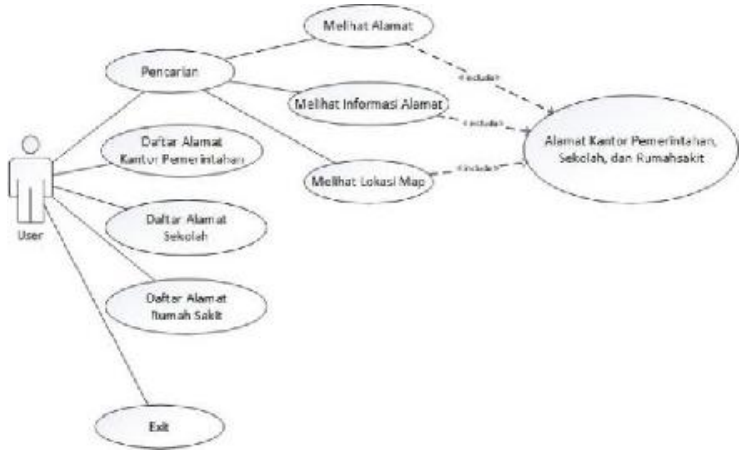

Gambar 3.4. Use Case Diagram User

\subsubsection{Data Flow Diagram}

Data Flow Diagram (DFD) Level 0 sering disebut Context Diagram (CD) adalah diagram yang terdiri dari suatu proses dan menggambarkan ruang lingkup suatu sistem. Dapat dilihat pada Gambar 3.5. Data Flow Diagram (DFD) Level 0.

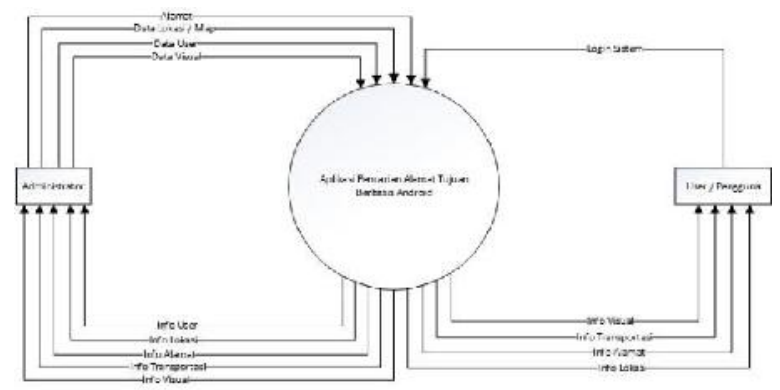

Gambar 3.5. Data Flow Diagram (DFD) Level 0

\subsubsection{Perancangan flowchat}

Perancangan flowchat dapat dilihat pada Gambar 3.6. Flowchart Aplikasi

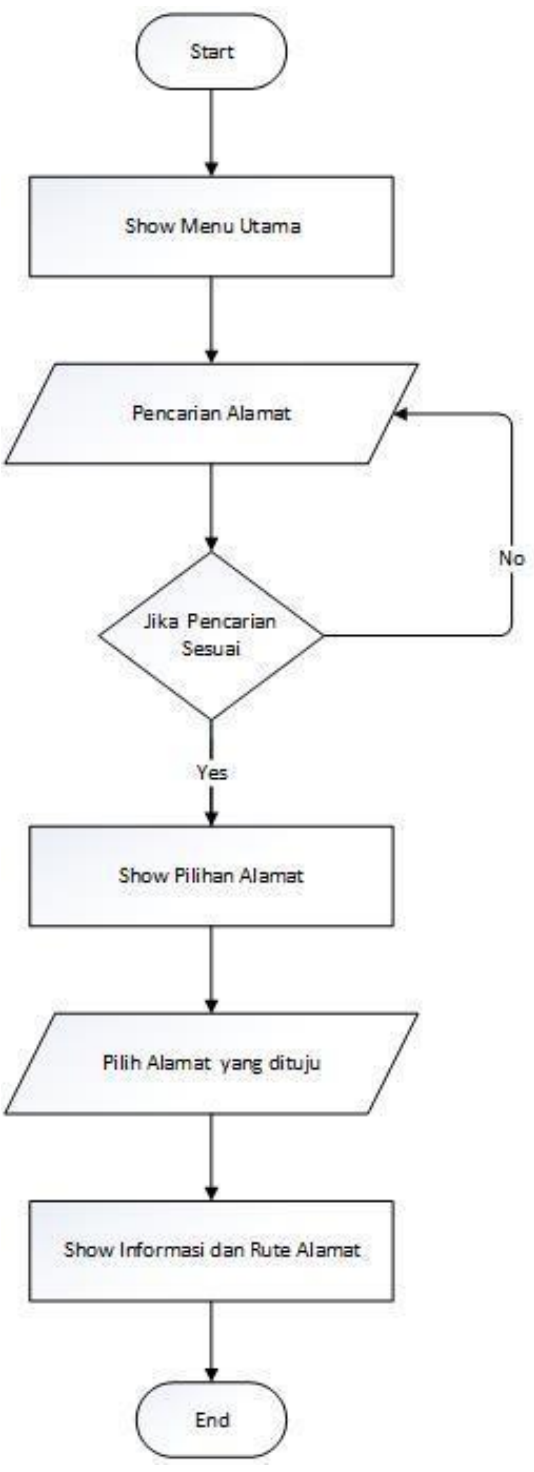

Gambar 3.6. Flowchart Aplikasi

\subsubsection{Perancangan Jaringan Client Server Aplikasi}

Gambaran perancangan jaringan client server dapat dilihat pada Gambar 3.7. skema jaringan client server. 


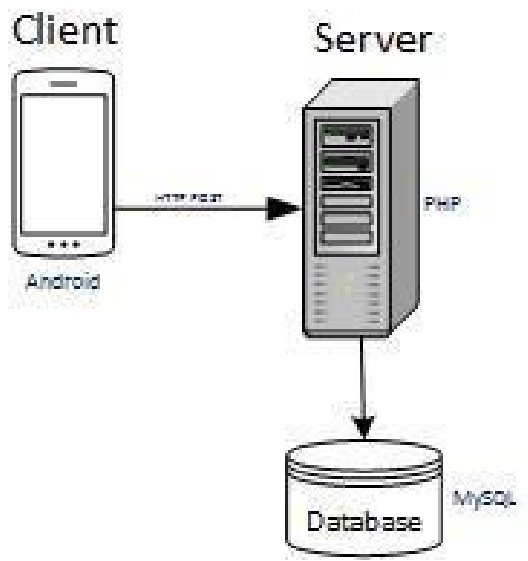

Gambar 3.7. Skema Jaringan Client Server

\section{HASIL PENELITIAN DAN PEMBAHASAN}

\subsection{Implementasi Sistem}

Implementasi sistem ini bertujuan untuk memastikan komponen-komponen dari sistem telah berfungsi sesuai dengan yang di harapkan. Percobaan yang sudah dilakukan diberbagai versi sistem operasi android dapat dilihat pada gambar 4.1. Uji coba pada android JellyBean
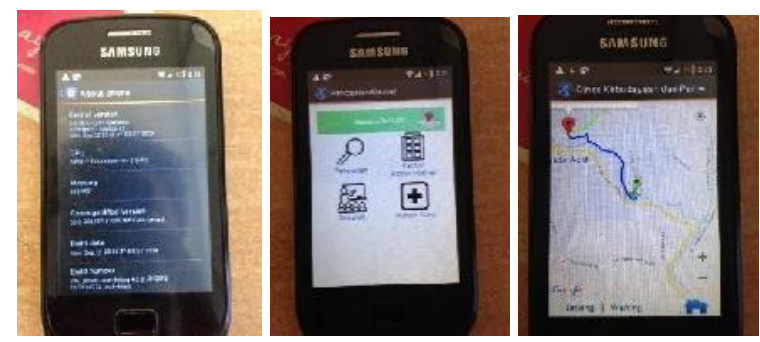

Gambar 4.1. Uji coba pada Android 4.2.2 JellyBean API 18
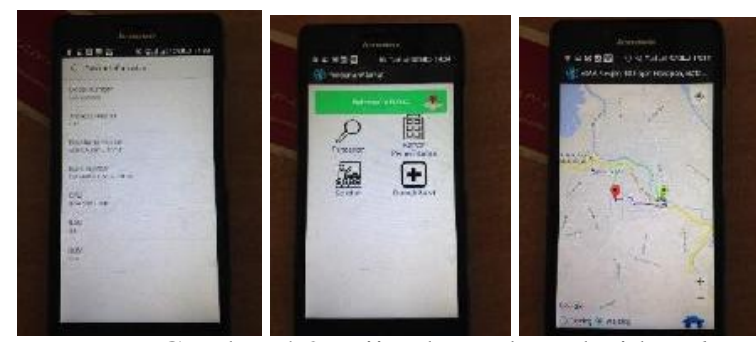

Gambar 4.2. Uji coba pada android Kitkat API 19
4.1.1. Implementasi Kebutuhan Perangkat

1. Spesifikasi Perangkat Keras

Tabel 4.1 Tabel Spesifikasi Perangkat Keras

\begin{tabular}{|l|l|l|}
\hline No. & Perangkat Keras & Keterangan \\
\hline 1 & Processor & AMD A8 \\
\hline 2 & Memory & 2 GB DDR3 \\
\hline 3 & Hard Drive & 500 GB \\
\hline 4 & Laptop & Lenovo G2 14 Inch \\
\hline 5 & Smartphone & Galaxy Mini 2 \\
\hline
\end{tabular}

2. Spesifikasi Perangkat Lunak

Tabel 4.2 Tabel Spesifikasi Perangkat Lunak

\begin{tabular}{|l|l|l|}
\hline No. & Perangkat Lunak & Keterangan \\
\hline 1 & Windows 10 Pro & Sistem Operasi \\
\hline 2 & Java & $\begin{array}{l}\text { Perangkat lunak untuk } \\
\text { melakukan coding }\end{array}$ \\
\hline \multirow{2}{*}{3} & $\begin{array}{l}\text { Android SDK } \\
\begin{array}{l}4.2 .2 \text { (Versi Jelly } \\
\text { Bean) for } \\
\text { Windows }\end{array}\end{array}$ & $\begin{array}{l}\text { Perangkat lunak untuk } \\
\text { debugging dari code } \\
\text { editor }\end{array}$ \\
\hline 4 & $\begin{array}{l}\text { Eclipse ADT } \\
\text { (eclipse versi } \\
4.2 .2)\end{array}$ & $\begin{array}{l}\text { Perangkat lunak untuk } \\
\text { code editor }\end{array}$ \\
\hline
\end{tabular}

4.2. Info sistem Aplikasi FLOAD

Application Name: FLOAD (Find Location Addres Detection) Project

Name: PencarianAlamat Package

Name: com.pencarianalamat Minimum

SDK: "9" Target SDK : "19" Compile

with: Eclipse ADT

\subsection{Hasil Observasi Lokasi}

a. Button Kantor Pemerintahan 22 Lokasi.

b. Button Sekolah 26 Lokasi.

c. Button Rumah Sakit 24 Lokasi.

\subsection{Pengujian}

\subsubsection{Implementasi Antarmuka (Interface)}

Implementasi antarmuka menggambarkan tampilan dari aplikasi yang dibangun yaitu aplikasi pencarian alamat tujuan. Berikut ini adalah implementasi antar muka dari aplikasi tersebut:

\subsubsection{Tampilan}

Tampilan Splash Screen dapat dilihat pada Gambar 4.3. User Interface Splash Screen ketika aplikasi dijalankan. 
Journal of Informatics and Computer Science Vol. 5 No. 1 April 2019

Universitas Ubudiyah Indonesia

e-ISSN : 2615-5346

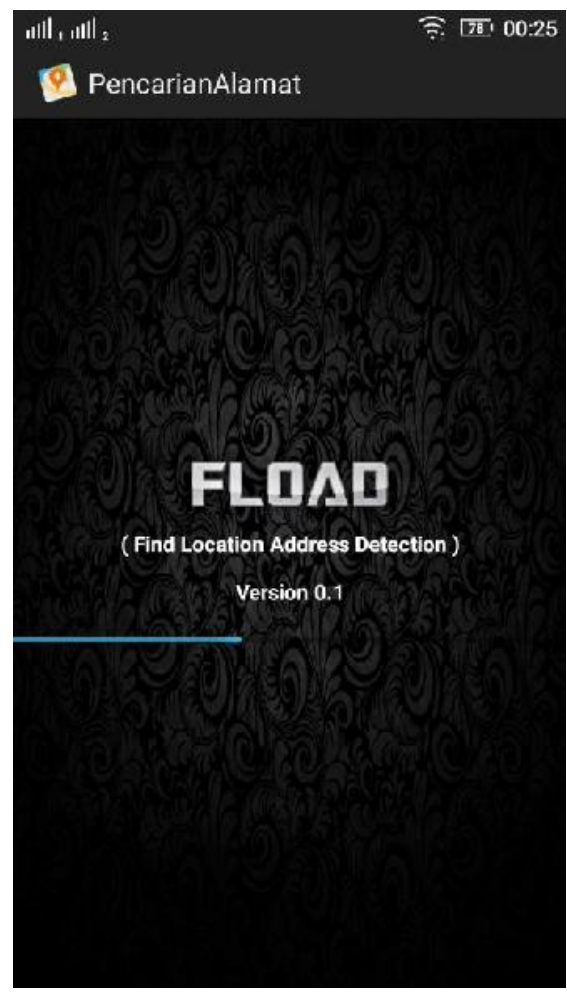

Gambar 4.3 User Interface Splash Screen ketika aplikasi dijalankan

\subsubsection{Halaman Utama Aplikasi}

Tampilan Halaman Utama Aplikasi dapat di lihat pada Gambar 4.4. Halaman Utama.

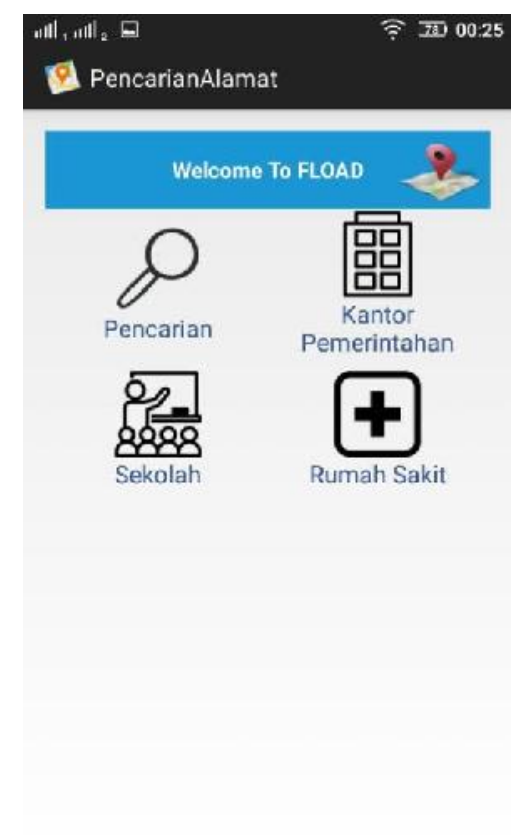

Gambar 4.4. Halaman Utama

\subsubsection{Menu Pencarian}

Gambaran secara luas cara kerja menu pencarian pada aplikasi ini bisa dilihat pada Gambar 4.5. Cara Kerja Form Pencarian

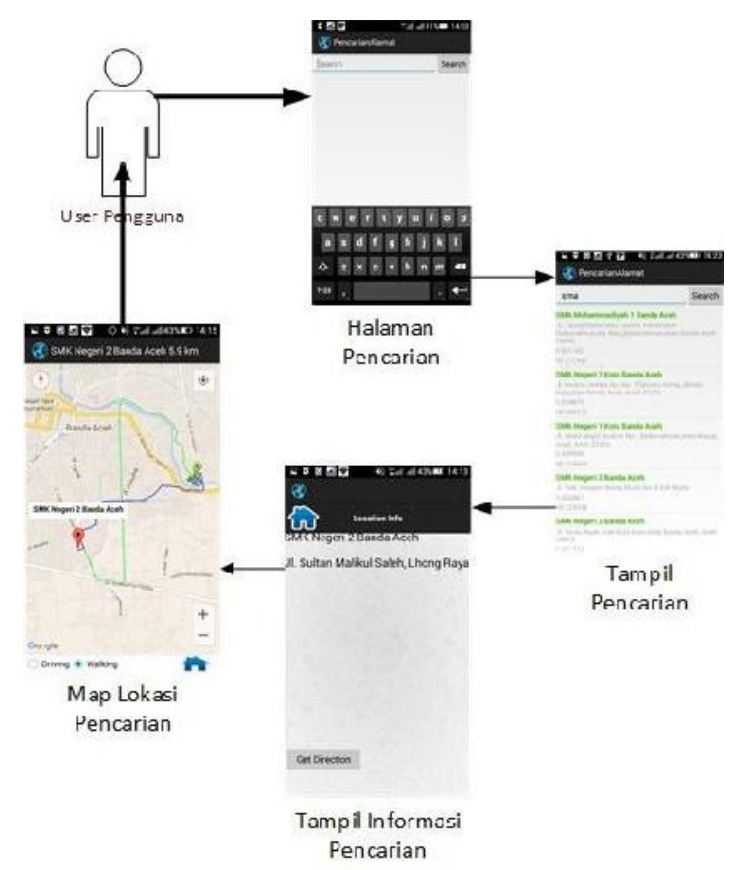

Gambar 4.5. Cara Kerja Form Pencarian

Pada Gambar 4.6. Form Pencarian, menampilkan form pencarian alamat tujuan.

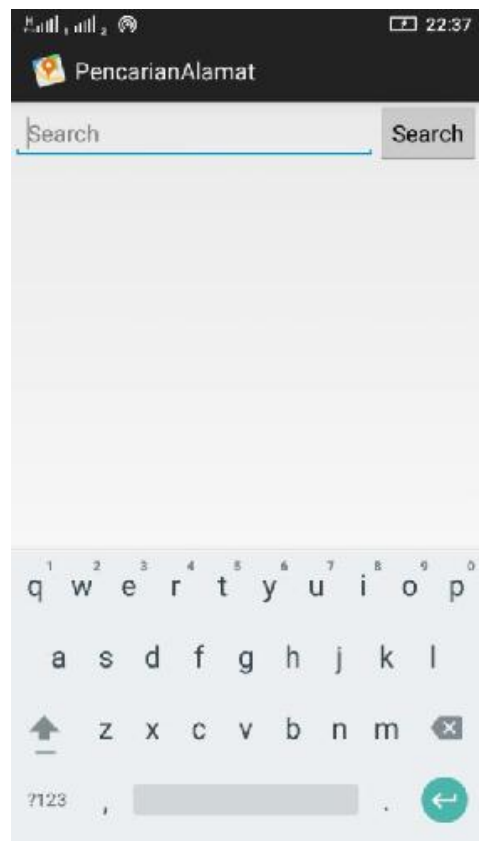

Gambar 4.6. Form Pencarian 
Journal of Informatics and Computer Science Vol. 5 No. 1 April 2019

Universitas Ubudiyah Indonesia

e-ISSN : 2615-5346

\subsubsection{Tampilan Hasil Pencarian}

Tampilan hasil pencarian dapat dilihat pada Gambar 4.7. Hasil Pencarian.

PencarianAlamat
dinas
Dinas Bina Marga Provinsi Aceh
Jalan Jenderal Sudirman No. 7 Banda Aceh
5.531357
95.303490
Dinas Kehutanan Provinsi Aceh
Jalan Sudirman No. 21 Banda Aceh
5.526268
95.303377
Dinas Kebudayaan dan Pariwisata Provinsi Aceh
Jalan Tgk. Chik Kuta Karang No.3 Banda Aceh
5.555663
95.324520
Dinas Kelautan dan Perikanan Provinsi Aceh
Jalan T. Malem No. 7 Banda Aceh
9.555794
95.326480

Dinas Keuangan Provinsi Aceh

Jalan T. Nyak Arief No. 120 Banda Aceh

5.562381

95.342917

Dinas Kesehatan Provinsi Aceh

Jalan Tgk Syech Mudawali No. 6 Banda. Aceh

Gambar 4.7. Hasil Pencarian

public void tampilkandata() $\{$ adapter $=$ new

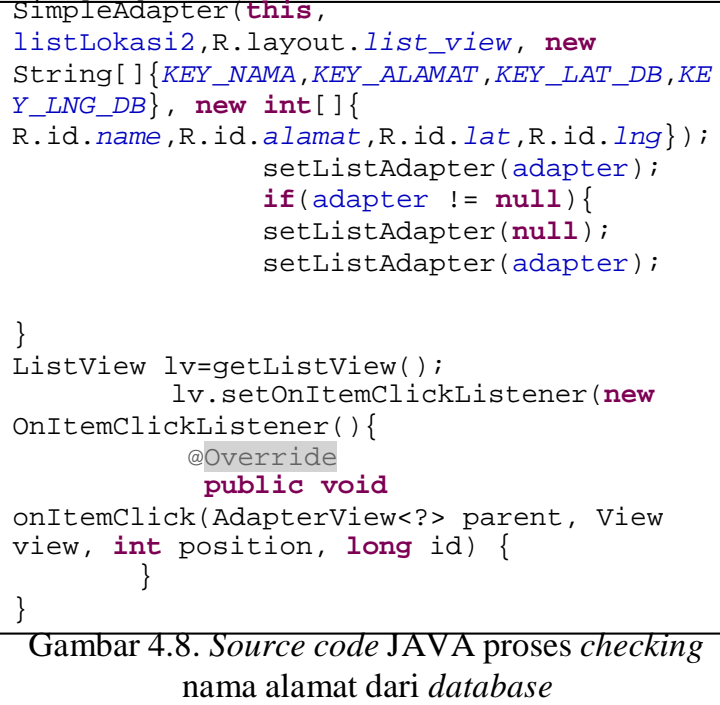

Gambar 4.8. Source code JAVA proses checking nama alamat dari database

\subsubsection{Tampilan Detail Pencarian data Alamat}

Tampilan Info Hasil Pencarian dapat dilihat pada Gambar 4.8. Info Hasil Pencarian.

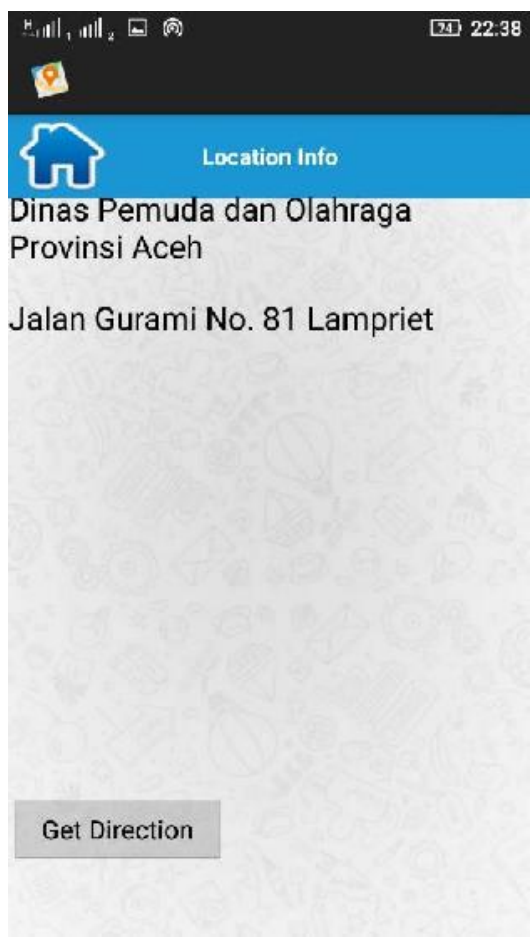

Gambar 4.9. Info Hasil Pencarian

\subsubsection{Tampilan Halaman Map Pencarian Alamat}

Tampilan Halaman Map Pencarian dengan Direction Driving dapat dilihat pada Gambar 4.9. Halaman Map Pencarian dengan Direction Driving.

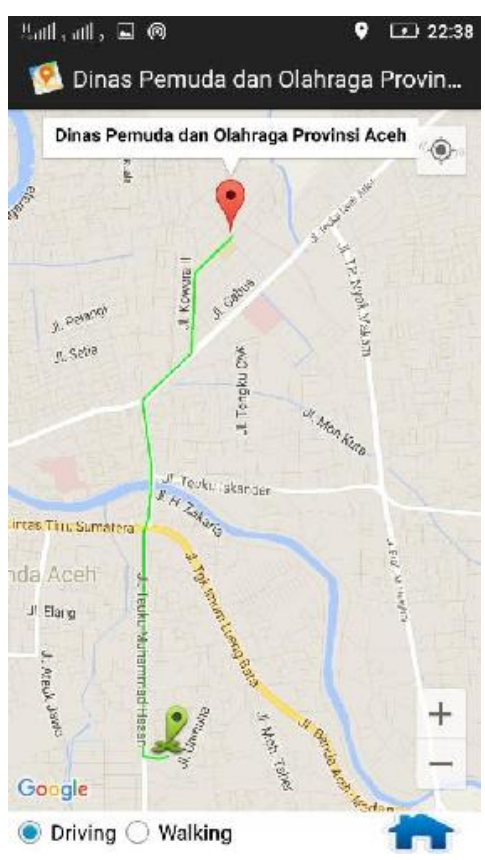

Gambar 4.10. Halaman Map Pencarian dengan Direction Driving 
Journal of Informatics and Computer Science Vol. 5 No. 1 April 2019

Universitas Ubudiyah Indonesia

e-ISSN : 2615-5346

Tampilan Halaman Map Alamat Tujuan dengan Direction Walking dapat dilihat pada Gambar 4.10. Halaman Map Pencarian dengan Direction Walking.
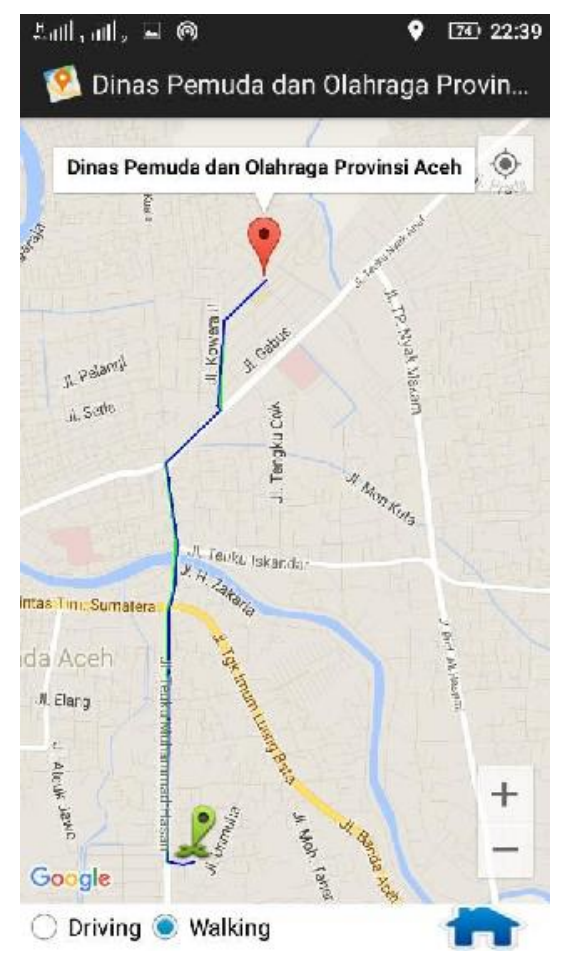

Gambar 4.11 Halaman Map Pencarian dengan Direction Walking

\subsection{Pengujian Database system}

Database berfungsi sebagai media penyimpanan data-data ataupun informasi penting. Database yang digunakan pada pengujian aplikasi ini ialah MySQL. Metode integrasi data pada database menggunakan webservice JSON dan webservice XML, sebagai jembatan pertukaran data dengan database MySQL.

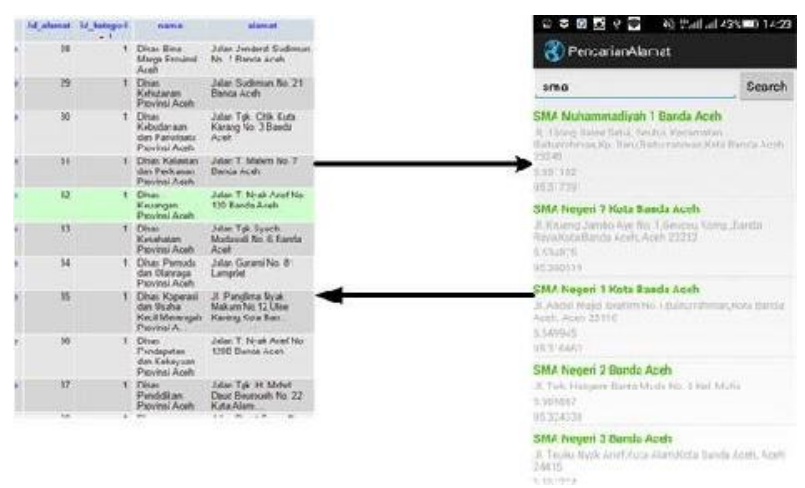

Gambar 4.12. Pengujian Database Sistem

\subsection{Pengujian Fitur Utama}

Proses pengujian fitur utama pada aplikasi FLOAD terdapat pada menampilkan informasi alamat yang tepat dan akurat, menu pencarian alamat berdasarkan nama alamat dan juga menampilkan direction atau penunjuk arah ke alamat yang dituju dengan dua mode, driving dan walking.

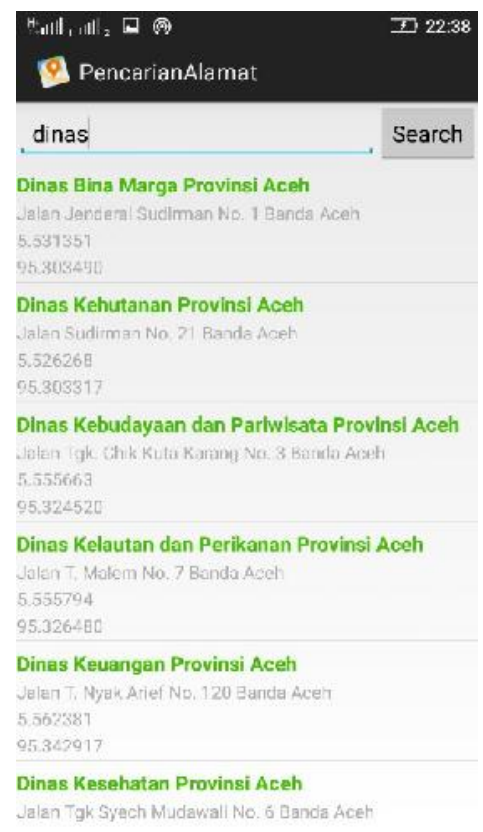

Gambar 4.13. Form Pencarian Alamat

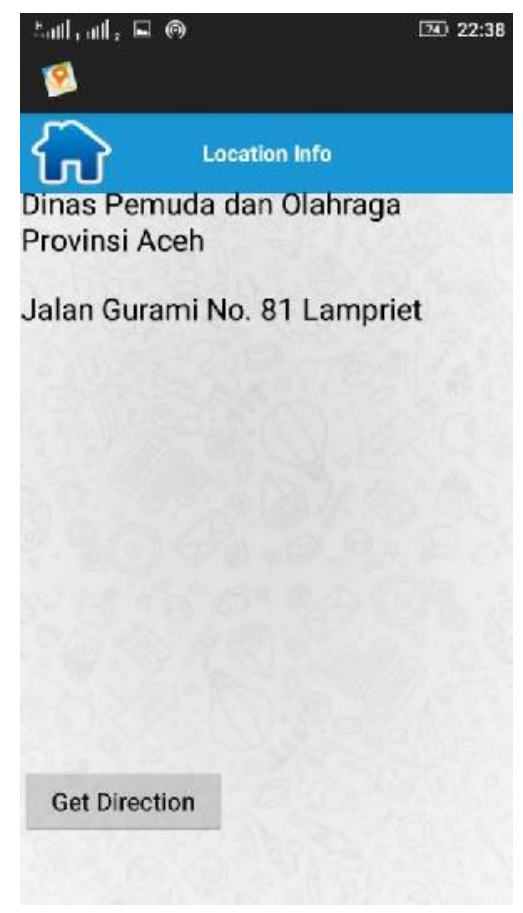

Gambar 4.14. Informasi Alamat

Botton Direction disini berfungsi untuk menampilkan halaman map yang berguna sebagai penunjuk atau pemandu pengguna ke lokasi tersebut. 


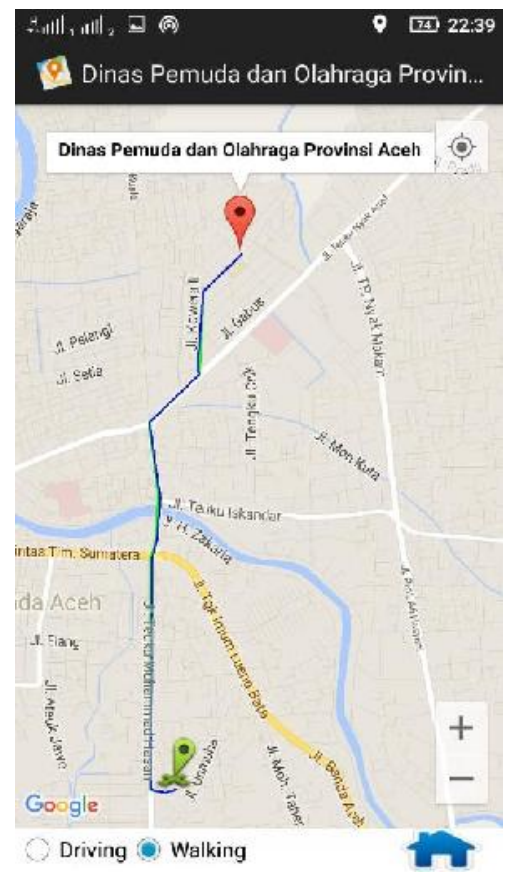

Gambar 4.5. Halaman Map

\subsection{Kelebihan dan Kekurangan}

Berdasarkan nilai rata-rata tertinggi dan terendah dari penilaian responden, maka aplikasi ini memiliki kelebihan dan kekurangan antara lain:

\subsubsection{Kelebihan}

1. Aplikasi dapat digunakan dengan mudah tanpa kesulitan (userfriendly).

2. Memudahkan mendapatkan lokasi alamat yang dituju dengan direction pada map aplikasi.

\subsubsection{Kekurangan}

1. Kurangnya Objek lokasi lain pada aplikasi FLOAD, menambahkan lokasi terminal, hotel, bank, Mesjid dan tempat pariwisata.

2. Belum bisa berjalan di banyak platform, kecuali Android.

3. Belum bisa berjalan offline.

4. Bebarapa responden menyarankan untuk menambahkan fitur save lokasi.

\section{KESIMPULAN DAN SARAN}

\subsection{Kesimpulan}

Pada bab ini di paparkan kesimpulan dari pengerjaan tugas akhir ini berdasarkan hasil perancangan Aplikasi pencarian alamat tujuan berbasis android dengan studi kasus di Banda Aceh, yaitu:
1. Aplikasi dapat dijalankan dengan baik pada perangkat yang mendukung MapFragment.

2. Aplikasi ini dapat berjalan dalam versi android tertentu seperti android 4.2.2 Jelly Bean, Android 4.4 kitkat.

3. Perancangan aplikasi FLOAD ini menggunakan pemrograman bahasa java sebagai algoritma dan xml sebagai pengatur interface (tampilan) dan MySQL sebagai database.

4. Dengan adanya aplikasi ini dapat membantu pengguna dalam hal menemukan alamat tujuan dengan tepat dan akurat.

\subsection{Saran}

Saran yang dapat di rekomendasikan oleh penulis dalam menyelesaikan tugas akhir ini adalah sebagai berikut:

1. Pengembangan selanjutnya aplikasi ini dapat dijalankan secara offline tanpa harus terhubung dengan internet.

2. Diharapkan dapat dikembangkan lebih lanjut pada platform mobile lainnya, seperti iOS, Blacberry OS dan Windows Phone.

3. Penambahan lokasi lain, seperti Alamat Bank, Hotel, Transportasi dan lokasi lain.

\section{DAFTAR PUSTAKA}

Adelia \& Setiawan, J. 2011. Implementasi Customer Relationship Management (CRM) pada Sistem Reservasi Hotel berbasisi Website dan Desktop. Jurnal Sarjana Teknik Informatika, vol 6, no.2, Juni 2011.

Afyenni, Rita. 2014. Perancangan Data Flow Diagram Untuk Sistem Informasi Sekolah (Studi Kasus Pada SMA Pembangunan Laboratorium UNP). Jurnal Teknik Informatika, vol 2, no 1 April 2014.

Arief, M. Rudianto. 2011. Pemrograman Web Dinamis Menggunakan PHP dan MySQL. Yogyakarta: ANDI.

Android, Developer. 2015. 'Android 6.0 Marshmallow'. Diakses pada tanggal 10 Februari 2016.

http://developer.android.com/intl/in/about/versions/ marshmallow/android-6.0.html.

Android, Developer. 2014. 'Android 5.0 Lolipop'. Diakses pada tanggal 10 Februari 2016. http://developer.android.com/intl/in/about/versions/lo llipop.html.

Damarullah, W \& Hamzah, A. 2013. Aplikasi Pengenalan Dan Pembelajaran Bahasa Korea 
(Hangeul) Berbasis Android. Jurnal SCRIPT, vol 1, no.1, Desember 2013.

Dwiyaniti, M., Ashari, D \& Nitisarmita KM. 2011. Aplikasi GPS Berbasis GSM Modem Pada Monitoring Bus. Jurnal Ilmiah Elite Elektro, vol 2, no 2, September 2011.

Fatta, Al Hanif. 2007. Analisis dan Perancangan

Sistem Informasi. Yogyakarta: Penerbit ANDI.

Fahmi, Nizar Sucipto \& Effendi, M. 2010. Perancangan Sistem Tracking Kuliner Tersertifikasi Halal Berbasis Android (Studi Kasus di Kota Malang).

Gianadevi, F \& Gorter, J. 2014. Aplikasi Pemungutan Suara Pemilihan Ketua Dan Wakil Ketua Bem Universitas Gunadarma Dengan Menggunakan Java Dan MySQL. Skripsi Sarjana 1 pada Universitas Gunadarma, Indonesia.

Haviluddin. 2011. Memahami Penggunaan UML (Unified Modelling Language). Jurnal Informatika Mulawarman, vol 6, no.1 February 2011.

Hernita, P. 2013. Android Programming with Eclipse. Yogyakarta: Penerbit Andi.

Huda, Arif Akbarul. 2013. Live Coding! 9 Aplikasi

Android buatan Sendiri. Yogyakarta: Penerbit ANDI.
188

Hal

;

Jakondar, Bakara. 2011. Perkembangan Sistem Satelit

Navigasi Global dan

Aplikasinya.

Kadir, Abdul. 2014. Pengenalan Sistem Informasi

Edisi Revisi. Penerbit

ANDI.

Mahdia, F \& Noviyanto, F. 2013. Pemanfaatan Google Maps API Untuk Pembangunan Sistem Informasi Manajemen Bantuan Logistik Pasca Bencana Alam Berbasis Mobile Web. Jurnal Sarjana Teknik Informatika, vol 1, no.1, Juni 2013.

Noviani, FW. 2011. Pengenalan tentang sejarah singkat mengenai Eclipse dan cara instalasi Eclipse.

Oktri, Mohammad Firdaus. 2013. Efektivitas Penggunaan Smartphone Dalam Mendukung Kegiatan Bisnis Pengusaha Muda Di Kota Bandung Menggunakan Technology Acceptance Model (TAM). Seminar Nasional IENACO.

Recky, TD., Sengkey, R \& Oktavian AL. 2015. Perancangan Sistem Informasi Akademik Sekolah Berbasis Web Studi Kasus Sekolah Menengah Atas Kristen 1 Tomohon. 